\title{
Cola Dissolution Therapy via Ileus Tube Was Effective for Ileus Secondary to Small Bowel Obstruction Induced by an Enterolith
}

\author{
Yuga Komaki, Shuji Kanmura, Akihito Tanaka, Mari Nakashima, Fukiko Komaki, \\ Hiromichi Iwaya, Shiho Arima, Fumisato Sasaki, Yuichiro Nasu, Shiroh Tanoue, \\ Shinichi Hashimoto and Akio Ido
}

\begin{abstract}
:
An 87-year-old bedridden woman developed intestinal obstruction caused by an enterolith or bezoar. Since the patient refused surgery, we administered $1,000 \mathrm{~mL} /$ day of cola via an ileus tube to dissolve the stone. Occlusion of the small intestine disappeared on day 6 . The excreted stones contained calcium phosphate, which is typical of enteroliths. We later confirmed that the retrieved stones could be dissolved in cola (Coca-Cola ${ }^{\circledR}$, $\mathrm{pH} 1.9)$ as well as 0.10 and $0.010 \mathrm{~mol} / \mathrm{L}$ hydrochloric acid $(\mathrm{pH} 1.0$ and 2.0 , respectively) and food-grade vinegar ( $\mathrm{pH}$ 2.6). These findings suggest that the enteroliths were dissolved by an acid-base reaction.
\end{abstract}

Key words: enterolith, intestinal obstruction, cola, acid-base reaction

(Intern Med 58: 2473-2478, 2019)

(DOI: 10.2169/internalmedicine.2745-19)

\section{Introduction}

Enteroliths are intestinal intraluminal stones (1). Enterolithiasis, or the formation of gastrointestinal concretions, is an uncommon medical condition that develops in the setting of intestinal stasis in the presence of intestinal diverticula, surgical enteroanastomoses, blind pouches, afferent loops, incarcerated hernias, small intestinal tumors, intestinal kinking from intra-abdominal adhesions, and stenosing or stricturing due to Crohn's disease and intestinal tuberculosis (2). Intraluminal causes of small bowel obstruction are infrequent and include ingestion of foreign bodies, bezoars, gallstone ileus, and parasitic infections, as well as iatrogenic causes such as postsurgical thrombus (3). Several previous studies have described the extremely rare obstruction of the small intestine due to stone impaction $(4,5)$. Recent reports have stated that enteroliths are most often diagnosed at laparotomy because they are rarely detectable radiographically unless they are calcified $(3,6,7)$. As a result, intestinal stones are most likely to be removed surgically.
We herein report a case in which cola dissolution therapy via an ileus tube was effective for relieving small bowel obstruction induced by an enterolith.

\section{Case Report}

An 87-year-old woman with Alzheimer's-type dementia and no family was a bedridden patient living in a nursing home with full assistance. She developed a fever and vomiting and was admitted to a local hospital. Upon the diagnosis of intestinal obstruction, a nasogastric tube was placed, and conservative treatment was carried out. However, while her symptoms improved, abdominal X-ray revealed persistent intestinal gas. The patient was then transferred to another hospital, where computed tomography (CT) identified a shadow in the upper small intestine, suspected of being a tumor, with a change in the intestinal caliber in the same location (Fig. 1A). She was finally transferred to our hospital for an examination under suspicion of a small bowel tumor.

Blood tests revealed a leukocyte count of $8.3 \times 10^{9} / \mathrm{L}$ and C-reactive protein level of $59.1 \mathrm{mg} / \mathrm{L}$. Due to long periods 
(A)

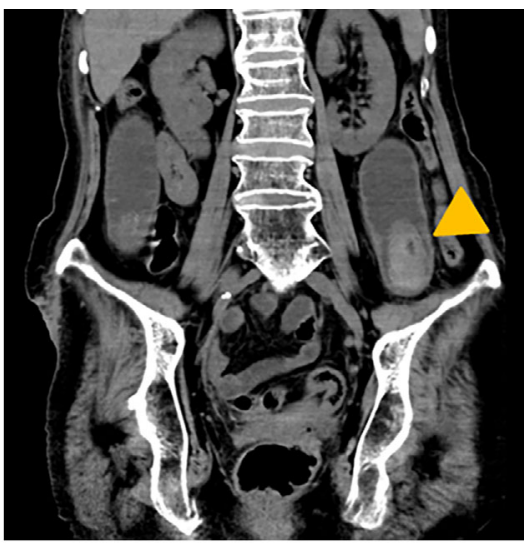

(B)

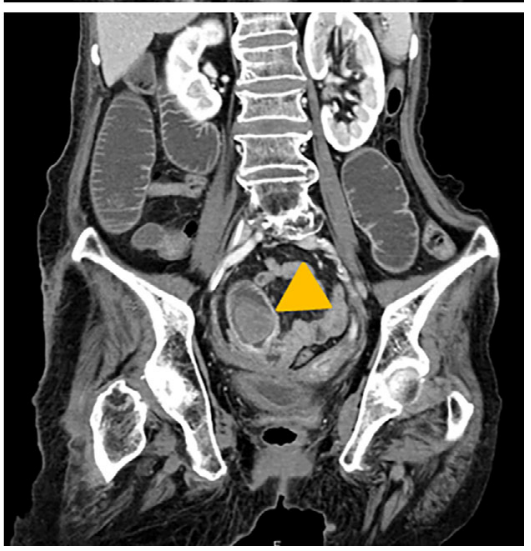

Figure 1. Abdominal plain computed tomography (CT) findings at the previous hospital (A) and enhanced CT findings on admission (B). CT detected a shadow in the small intestine, appearing as a high-intensity area (arrowhead). B shows that this area had moved to the anal side of the intestine on admission.

of fasting, hypoproteinemia had developed. The liver deviation enzyme and biliary enzyme values were normal, except for that of aspartate aminotransferase, which was $48 \mathrm{U} / \mathrm{L}$. The remaining laboratory findings were within normal limits. Plain abdominal radiography showed an expanded small intestine. Abdominal CT showed biliary emphysema along with a large, high-intensity area in the small intestine with Hounsfield Unit (HU) values of 31 to 134 . According to the CT findings obtained at the previous hospital, the substance in the small intestine had moved toward the distal small intestine (Fig. 1B). On abdominal ultrasonography, the substance was mobile with an acoustic shadow (Fig. 2). We therefore suspected the entity to be a stone, specifically an enterolith, gallstone, or bezoar.

We inserted an ileus tube using an ultra-slim transnasal endoscope (XP260N; Olympus, Tokyo, Japan) to resolve the patient's intestinal obstruction. A small bowel series performed with amidotrizoate administration via an ileus tube showed no diverticula, and the substance was observed to have become stuck in the small intestine (Fig. 3A and B). We determined that it was not a gallstone because there was no biliary-enteric fistula on the duodenal series (Supplementary material). We suspected that the intestinal obstruction had been caused by a bezoar, as we noted several stones

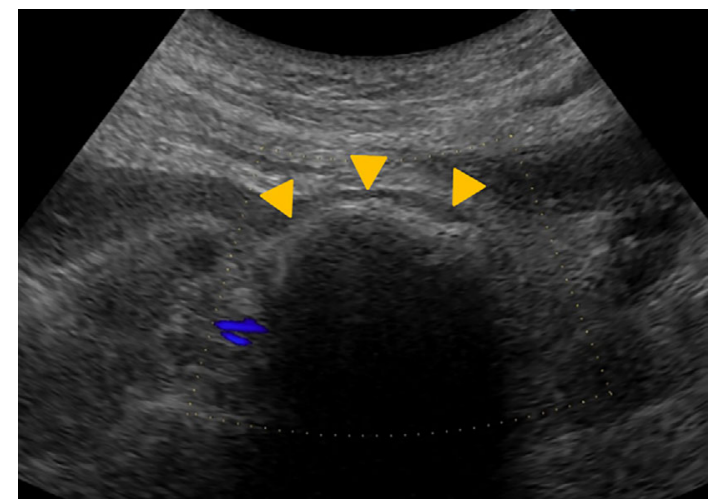

Figure 2. Abdominal ultrasonography findings on admission. A moveable substance with an acoustic shadow was detected in the small intestine.

(A)

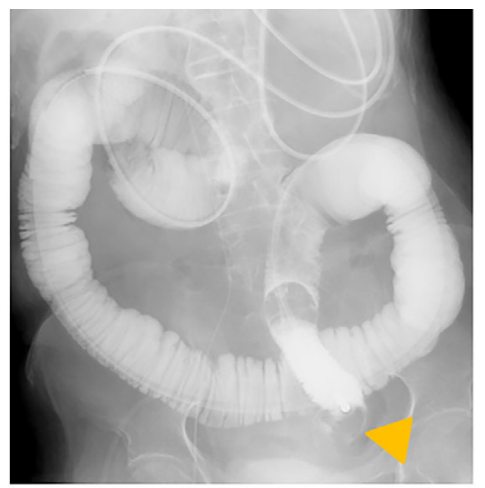

(B)

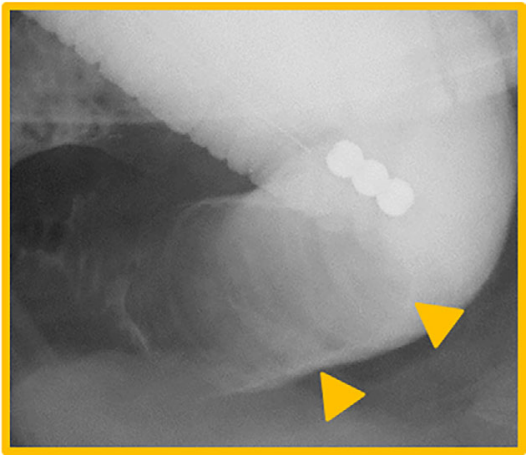

Figure 3. Small intestine enema after ileus tube insertion. (A) Full abdominal image during the small bowel series. There was no diverticulum in the patient's small intestine. (B) Magnified image of the arrowhead in (A). A large substance (arrowheads) had become stuck in the small intestine.

containing a small amount of hair in the patient's stomach. We recommended that she undergo surgery to remove the intestinal substance, but she and her guardian refused surgery. We therefore decided to inject $1,000 \mathrm{~mL} /$ day of cola $\left(\right.$ Coca-Cola ${ }^{\circledR}$ ) via the ileus tube to dissolve the stone, as per a previous report (8).

We injected $500 \mathrm{~mL}$ of cola twice a day. We clamped the ileus tube for 30 minutes after each injection and then unclamped it. The substance in the small intestine began shrinking the day after the first injection (Fig. 4A) and disappeared completely by day 6 (Fig. 4B); the ileus also resolved. We withdrew the ileus tube and restarted the pa- 
(A)

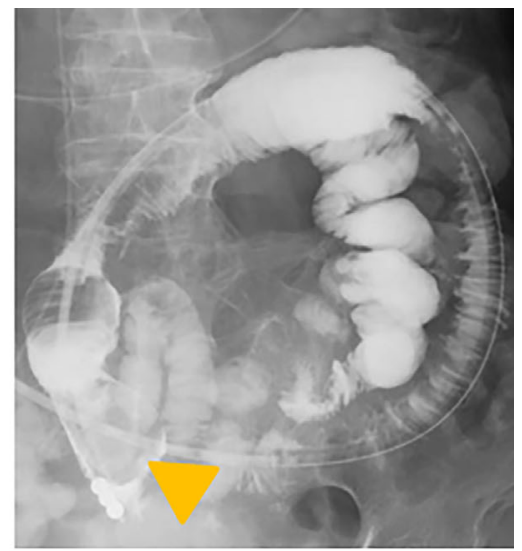

(B)

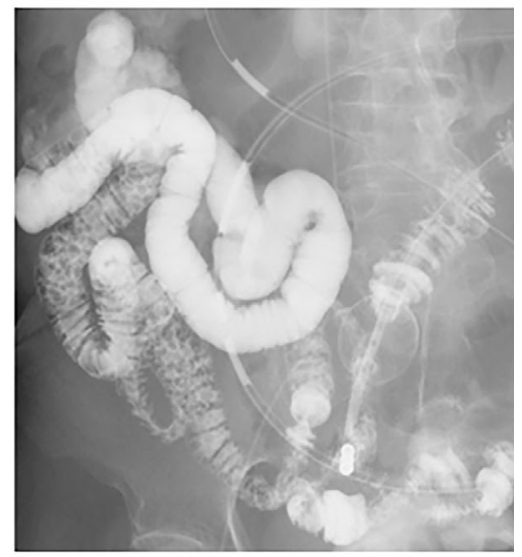

(C)

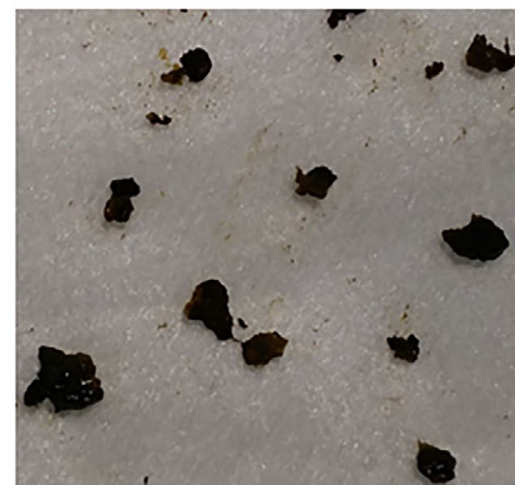

Figure 4. X-ray findings on Day 2 (A) and Day 6 (B) after starting cola injection and collecting the stones $(\mathrm{C})$. The substance in the small intestine shrank on Day 2 and had disappeared by Day 6. Dispersed stones were excreted in the stool. The arrowhead shows the substance in the small intestine.

tient's oral intake, after which she was transferred back to the previous hospital to continue rehabilitation.

We later retrieved several stones that had been excreted into the patient's stool (Fig. 4C). An analysis revealed that they consisted of calcium phosphate, bilirubin calcium, and cholesterol, which were consistent with the ingredients of an enterolith, as described in previous reports $(9,10)$, but not those of a bezoar. To determine whether or not the calculi could be dissolved in solvents other than cola, 5-mg samples were placed in $20 \mathrm{~mL}$ of each of the following solvents at $25^{\circ} \mathrm{C}$ : Coca-Cola ${ }^{\circledR}(\mathrm{pH} 1.9)$, carbonated water $(\mathrm{pH} 3.6)$, and purified water ( $\mathrm{pH}$ 7.0). When soaked gently in cola for 3 hours, the calculus became lighter $(1 \mathrm{mg})$; by contrast, its weight did not change markedly after soaking in carbonated water or purified water (Fig. 5, Table). Since solvents containing carbonic acid are likely to change in $\mathrm{pH}$ as carbonic acid escapes, we measured the $\mathrm{pH}$ of Coca-Cola ${ }^{\circledR}$ and carbonated water samples 3 hours after their containers had been opened. The $\mathrm{pH}$ of Coca-Cola ${ }^{\circledR}$ showed almost no change (2.0), while that of carbonated water increased (4.1) (Table). In order to investigate whether or not the calculi could be dissolved by acidic solvents other than cola, 5-mg samples were placed in $20 \mathrm{~mL}$ of each of the following solvents: $0.10 \mathrm{~mol} / \mathrm{L}$ hydrochloric acid $(\mathrm{HCl} ; \mathrm{pH} 1.0), 0.010$ $\mathrm{mol} / \mathrm{L} \mathrm{HCl}(\mathrm{pH} 2.0)$, and food-grade vinegar $(\mathrm{pH} 2.6)$ under the same conditions as the cola dissolution experiment. After soaking gently for 3 hours, the samples were lighter under all conditions: $0.10 \mathrm{~mol} / \mathrm{L} \mathrm{HCl}(1 \mathrm{mg}), 0.010 \mathrm{~mol} / \mathrm{L} \mathrm{HCl}(2$ $\mathrm{mg}$ ), and food-grade vinegar $(2 \mathrm{mg}$ ) (Table).

\section{Discussion}

We encountered a rare case in which cola dissolution therapy via an ileus tube was effective for managing small bowel obstruction induced by an enterolith. Enteroliths are stones that develop within the intestinal tract. They are usually encountered within diverticula or surgically created intestinal pouches, or proximal to an obstruction in the small or large bowel (11). In particular, enteroliths have been reported in approximately 50 cases of Meckel's diverticula (12). Enterolith formation is thought to be attributable to bowel hypomotility or stasis. Several previous studies have noted that such stasis alters the bacterial flora and promotes bacterial growth. Bacteria may convert cholic acid to insoluble deoxycholic acid (5), and precipitation of the unconjugated bile acids within the bowel lumen leads to stone formation (11). Our patient had no diverticula but was almost completely bedridden due to dementia. Her persistent bedridden state reduced intestinal peristalsis, which facilitated the formation of an enterolith.

Primary enteroliths are formed in the small bowel, while secondary enteroliths (gallstones) are formed in the gallbladder. In the differential diagnosis of a small bowel obstruction in an elderly patient, one should always consider gallstone ileus, which occurs when a gallstone passes through a biliary-enteric fistula (13). In our case, we were initially unsure if the patient had gallstone ileus because biliary emphysema was already present when she was admitted to our hospital. However, we detected no biliary-enteric fistula on a small bowel series and thus concluded that the stone was a primary enterolith.

Surgical or endoscopic procedures have been reported to be useful for removing intestinal stones when ileus occurs $(14,15)$. We ultimately administered cola (Coca-Cola ${ }^{\circledR}$ ) to our patient via an ileus tube because she refused invasive treatment (i.e., surgery) due to the suspicion that the material obstructing the small intestine was only a bezoar. The material finally dissolved in the cola, and fragments of the stone were excreted. However, the components of the stone were not those typically found in bezoars, such as tannic 
(A)

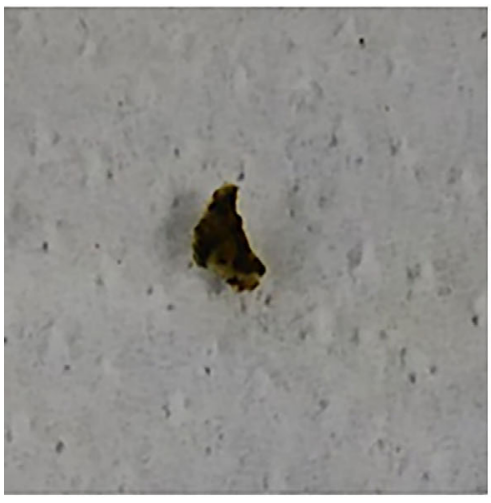

(D)

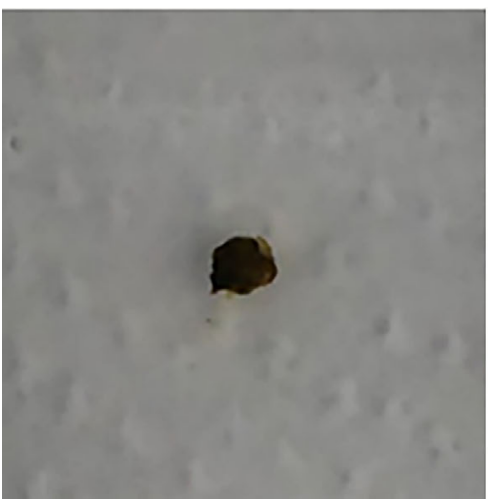

(B)

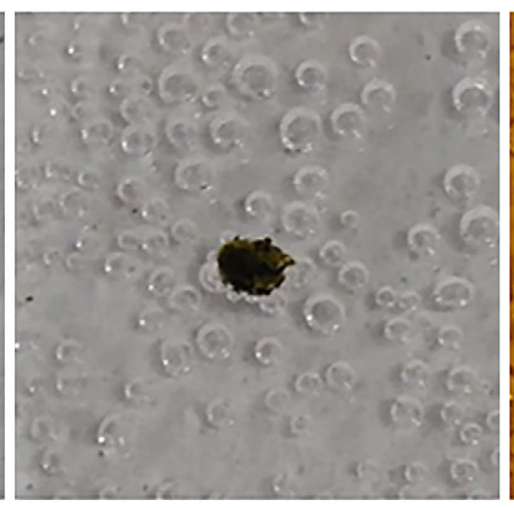

(E)

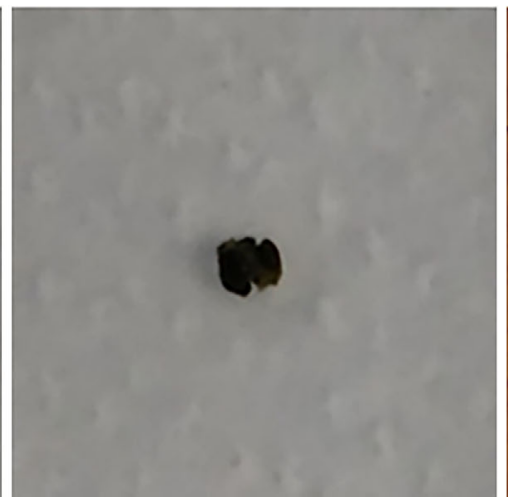

(C)

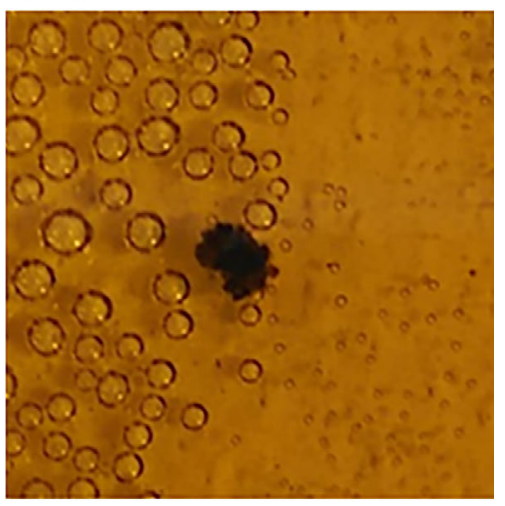

$(\mathrm{F})$

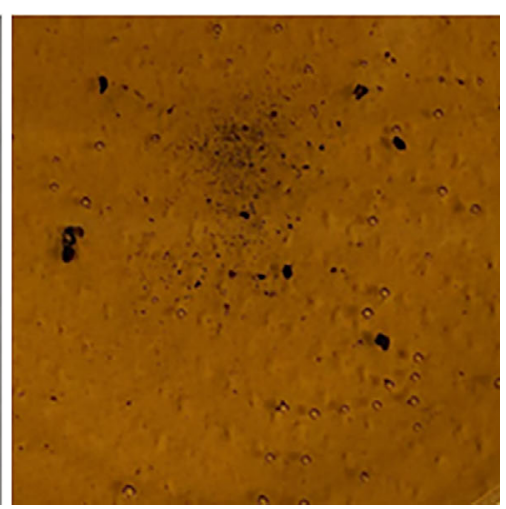

Figure 5. A calculus before and after being placed in $20 \mathrm{~mL}$ of purified water [before (A), after (D)], carbonated water [before (B), after (E)], and Coca-Cola ${ }^{\circledR}$ [before (C), after (F)]. The calculus became lighter in Coca-Cola ${ }^{\circledR}$, but its weight did not change in purified water or carbonated water.

Table. Calculus and Solvents before and after Calculi were Placed in Each Solvent.

\begin{tabular}{lcccccc}
\hline & Purified water & Carbonated water & Coca-Cola ${ }^{\circledR}$ & HCl 0.10 mol/L & HCl 0.010 mol/L & $\begin{array}{c}\text { Food-grade } \\
\text { vinegar }\end{array}$ \\
\hline $\begin{array}{l}\text { pH of each solvent before } \\
\text { dissolution of calculus }\end{array}$ & 7.0 & 3.6 & 1.9 & 1.0 & 2.0 & 2.6 \\
$\begin{array}{l}\text { Weight of each calculus } \\
3 \text { h after dissolution }\end{array}$ & $5 \mathrm{mg}$ & $5 \mathrm{mg}$ & $1 \mathrm{mg}$ & $1 \mathrm{mg}$ & $2 \mathrm{mg}$ & $2 \mathrm{mg}$ \\
$\begin{array}{l}\text { pH of each solvent } \\
\text { h h after container opening } \\
\text { pH of each solvent }\end{array}$ & 7.0 & 4.1 & 2.0 & $\mathrm{NA}$ & $\mathrm{NA}$ & $\mathrm{NA}$ \\
3 h after dissolution & $\mathrm{NA}^{*}$ & $\mathrm{NA}^{*}$ & $\mathrm{NA}^{*}$ & 1.2 & 2.1 & 2.7 \\
\hline
\end{tabular}

The weight of each calculus before dissolution was $20 \mathrm{mg}$. $\mathrm{HCl}$ : hydrochloric acid

* We were unable to measure the $\mathrm{pH}$ of each solvent $3 \mathrm{~h}$ after dissolution because the amount of calculi was insufficient to perform all experiments.

acid or keratin protein.

A previous study noted that the non-oxyntic mucosa of the small bowel creates an alkaline environment in which calcium oxalate crystals form within the bile and other bowel contents, resulting in enteroliths (12). Reports on the histology of enteroliths have demonstrated the presence of bile salts $(1,12)$. In the present case, the HU values of the enterolith on CT ranged from 31 to 134, and the excreted enterolith contained calcium phosphate, bilirubin calcium, and cholesterol. As biliary cholesterol and bile salts are components of bile (16), bile may have been one of the constituents of the present enterolith, consistent with a previous report (12). Furthermore, calcium phosphate is a substance formed in an alkaline environment. The mean HU densities of calcium and non-calcified stones were reported to be 105 and 31 , respectively $(17,18)$, findings that are consistent with those of this study.

There have been no reports in which cola was used to treat enteroliths. Because calcium phosphate is one of the main components of enteroliths and forms in an alkaline en- 
vironment, we considered the possibility that an acid-base reaction might be involved. The $\mathrm{pH}$ of Coca-Cola ${ }^{\circledR}$ is 1.9 , which is more acidic than that of $0.010 \mathrm{~mol} / \mathrm{L} \mathrm{HCl}$. We compared the $\mathrm{pH}$ of Coca-Cola ${ }^{\circledR}$ with that of other solvents, such as purified water and carbonated water (7.0 and 3.6, respectively). As both Coca-Cola ${ }^{\circledR}$ and carbonated water include carbon dioxide, we also measured the $\mathrm{pH}$ of each solvent after 3 hours of exposure to open air. The $\mathrm{pH}$ of CocaCola $^{\circledR}$ after 3-hours exposure was 2.0, demonstrating little change from baseline. However, the $\mathrm{pH}$ of carbonated water after exposure was 4.1. These findings suggest that CocaCola ${ }^{\circledR}$ contains ingredients in addition to carbonic acid that maintain its acidity, although what these are is unclear. Of note, in our experiments, enterolith fragments dissolved in Coca-Cola ${ }^{\circledR}$ but not in carbonated water.

Iwamuro reported that enteroliths removed surgically from patients with Crohn's disease could be dissolved by citric acid (9). In order to investigate whether or not an acid-base reaction was involved in the dissolution of enterolith fragments in this study, we assessed their dissolution in several solvents: $0.10 \mathrm{~mol} / \mathrm{L} \mathrm{HCl}(\mathrm{pH} 1.0), 0.010 \mathrm{~mol} / \mathrm{L} \mathrm{HCl}(\mathrm{pH}$ 2.0), and food-grade vinegar $(\mathrm{pH} 2.6)$, the last of which contains acetic acid. As mentioned above, the enterolith fragments were almost completely dissolved in each solvent, but to a lesser degree in $0.10 \mathrm{~mol} / \mathrm{L}$ of $\mathrm{HCl}$ than in 0.010 $\mathrm{mol} / \mathrm{L}$ of $\mathrm{HCl}$ and food-grade vinegar. $\mathrm{HCl}$ reacts with calcium phosphate $\left[\mathrm{Ca}_{3}\left(\mathrm{PO}_{4}\right)_{2}\right]$ to form calcium chloride $\left(\mathrm{CaCl}_{2}\right)$ and phosphoric acid $\left(\mathrm{H}_{3} \mathrm{PO}_{4}\right)$, both of which are watersoluble substances. Similarly, acetic acid $\left(\mathrm{CH}_{3} \mathrm{COOH}\right)$ reacts with calcium phosphate to form calcium acetate $\left[\mathrm{Ca}\left(\mathrm{CH}_{3}\right.\right.$ $\mathrm{COO})_{2}$ ] and phosphoric acid, both of which are also watersoluble. While some of the ingredients of Coca-Cola ${ }^{\circledR}$ are unknown, since this is proprietary information, there is a high possibility that Coca-Cola ${ }^{\circledR}$ underwent an acid-base reaction with the enterolith, thus dissolving it. Enteroliths that contain substances formed in an alkaline environment may also be dissolved in Pepsi-Cola ${ }^{\circledR}$, as it has a pH of 2.7 and may undergo a similar acid-base reaction as Coca-Cola ${ }^{\circledR}$.

Several limitations associated with the present study warrant mention. First, because of the small size of the retrieved enterolith fragments, we were unable to determine the proportions of the enterolith components. Since the stones that were excreted were calculi that formed after the injection of cola, most of the original enterolith was assumed to have dissolved in the cola. Second, bilirubin calcium and cholesterol, which were present in the analyzed calculi in our case, are often the primary components of gallstones. Less frequently, calcium phosphate has also been reported in gallstones $(19,20)$. However, a previous study showed that both gallbladder and common bile duct strongly inhibited the crystallization of calcium phosphate and therefore reduced its formation (21). Furthermore, calcium phosphate is formed in an alkaline environment, as mentioned above. Indeed, previous studies reported that calcium phosphate was a component of enteroliths $(9,22)$. In our case, we did not detect a biliary-enteric fistula. Morioka previously reported the case of a true enterolith containing bilirubin calcium in the absence of a biliary-enteric fistula (23). Based on the present and previous findings, we concluded that the patient's intestinal stone was an enterolith. The detailed ingredients of Coca-Cola ${ }^{\circledR}$ and Pepsi-Cola ${ }^{\circledR}$ are unclear. Nevertheless, the therapeutic effects in this case were considered to have been caused by the cola, which remains in an acidic state even when the carbonic acid contained therein evaporates.

In conclusion, we reported for the first time the efficacy of cola dissolution therapy via an ileus tube for managing mechanical ileus induced by an enterolith. While many studies have reported the success of invasive treatments, such as surgery, conservative treatment by dissolving the calculus in cola may be viable, at least for ileus caused by primary enteroliths.

The authors state that they have no Conflict of Interest (COI).

\section{References}

1. Abtar HK, Mneimneh M, Hammoud MM, Zaaroura A, Papas YS. Primarily proximal jejunal stone causing enterolith ileus in a patient without evidence of cholecystoenteric fistula or jejunal diverticulosis. Case Rep Surg 2016: 8390724, 2016.

2. Gurvits GE, Lan G. Enterolithiasis. World J Gastroenterol 20: 17819-17829, 2014.

3. Chaudhery B, Newman PA, Kelly MD. Small bowel obstruction and perforation secondary to primary enterolithiasis in a patient with jejunal diverticulosis. BMJ Case Rep 2014: 203833, 2014.

4. Siddiqui AA. Rare cause of small bowel obstruction-enterolith. Rawal Med J 36: 246-247, 2011.

5. Cho YS, Lee TH, Hwang SO, et al. Electrohydraulic lithotripsy of an impacted enterolith causing acute afferent loop syndrome. Clin Endosc 47: 367-370, 2014.

6. Woods K, Williams E, Melvin W, Sharp K. Acquired jejunoileal diverticulosis and its complications: a review of the literature. Am Surg 74: 849-854, 2008.

7. Winters L, Krell RW, Machado-Aranda D. Abdominal pain and faeculent vomiting in a 64-year-old woman. BMJ Case Rep 2016: bcr2015212826, 2016.

8. Endo K, Kakisaka K, Suzuki Y, Matsumoto T, Takikawa Y. Obstructive bezoars of the small bowel treated with Coca-Cola Zero through a long intestinal tube and endoscopic manipulation. Intern Med 56: 3019-3022, 2017.

9. Iwamuro M, Urata H, Hiraoka S, et al. A Calcium enterolith in a patient with Crohn's disease and its in vitro dissolubility in citric acid. Case Rep Gastrointest Med 2017: 2951547, 2017.

10. Paige ML, Ghahremani GG, Brosnan JJ. Laminated radiopaque enteroliths: diagnostic clues to intestinal pathology. Am J Gastroenterol 82: 432-437, 1987.

11. Capaccio E, Zuccarino F, Gauglio C, Pretolesi F, Derchi LE. Acute obstruction of the afferent loop caused by an enterolith. Emerg Radiol 13: 201-203, 2007.

12. Dill T, Sugo E, McManus B. Enteroliths and multiple neuroendocrine tumours in a Meckel's diverticulum. Pathology 49: 319-322, 2017.

13. Yadav G, Husain S, Shukla R, Patidar R, Luthra R. A Rare case of calcified enterolith presenting as subacute intestinal obstruction. Indian J Surg 77: 327-328, 2015.

14. Steenvoorde P, Schaardenburgh P, Viersma JH. Enterolith ileus as a complication of jejunal diverticulosis: two case reports and a re- 
view of the literature. Dig Surg 20: 57-60, 2003.

15. Nonaka $T$, Inamori $M$, Kessoku $T$, et al. Acute obstructive cholangitis caused by an enterolith in a duodenal diverticulum. Endoscopy 42 (Suppl): E204-E205, 2010.

16. Sarles H, Hauton J, Planche NE, Lafont H, Gerolami A. Diet, cholesterol gallstones, and composition of the bile. Am J Dig Dis 15: 251-260, 1970.

17. Motley G, Dalrymple N, Keesling C, Fischer J, Harmon W. Hounsfield unit density in the determination of urinary stone composition. Urology 58: 170-173, 2001.

18. Janowitz P, Zoller A, Swobodnik W, Wechsler JG, Schumacher KA, Ditschuneit H. Computed tomography evaluation of radiolucent gallstones in vivo. Gastrointest Radiol 15: 58-60, 1990.

19. Cariati A. Gallstone classification in Western countries. Indian J Surg 77 (Suppl): 376-380, 2015.

20. Cariati A, Cetta F. Rokitansky-Aschoff sinuses of the gallbladder are associated with black pigment gallstone formation: a scanning electron microscopy study. Ultrastructural Pathol 27: 265-270, 2003.

21. Sutor DJ, Percival JM. Presence or absence of inhibitors of crystal growth in bile. 1. Effect of bile on the formation of calcium phosphate, a constituent of gallstones. Gut 17: 506-510, 1976.

22. Shrestha AL, Shrestha P. Recurrent enterolithiasis small bowel obstruction: a case seldom described. Case Rep Gastrointest Med 2017: 4684182, 2017.

23. Morioka H, Ueda $Y$, Nishihira $T$, et al. True enteroliths linked to non-specific multiple ulcers of the small intestine: report of a case. Clin J Gastroenterol 6: 368-372, 2013.

The Internal Medicine is an Open Access journal distributed under the Creative Commons Attribution-NonCommercial-NoDerivatives 4.0 International License. To view the details of this license, please visit (https://creativecommons.org/licenses/ by-nc-nd/4.0/).

(C) 2019 The Japanese Society of Internal Medicine Intern Med 58: 2473-2478, 2019 